\title{
Teaching Practical Research Data Management
}

\author{
Skills through Online Training and Data
}

\section{Management Plan Creation}

Dr Beth Montague-Hellen, Dr Holly Ranger

University of Nottingham Libraries, University of Nottingham, UK

\section{ABSTRACT}

Introduction Research Data Management is growing in importance as a field as the amount of data which researchers must manage increases. It is important to ensure that postgraduate researchers are trained through engaging courses which practically prepare them to fulfil the data management requirements of funders and Universities, and to carry out their research in a transparent and effective manner. Description of program We present a case study of the development and delivery of a new Research Data Management (RDM) online course for postgraduates and early career researchers. The course implements pedagogical theory and a reverse design paradigm in the development of library training provision enabling the creation of a course vastly more relevant to academic research practice than our previous offering. The course uses a simplified Data Management Plan to introduce students to Research Data Management Concepts, and by asking them to apply this knowledge, lifts the course from one which simply asks students to remember knowledge to one which shows them how to apply this knowledge in a way that is applicable to their own research. The course has been evaluated for effectiveness and student engagement at 3 months. Next steps 
Although some analysis of the effectiveness of the new course has been undertaken, the course will continue to be evaluated. Although the course was developed for PGRs it has been popular with ECRs and Professional support staff and we will investigate how we can further meet the needs of these groups. The platform used will allow for the topics most often accessed to be identified and the course, and the University's training provision will be adjusted based on this evidence. We hope that other institutions will be able to learn from our experience and implement similar courses.

\section{KEYWORDS}

Research Data Management, Data Management Plan, Moodle, Graduate, PGR, ECR

\section{INTRODUCTION}

There are few fields of research which do not now involve collecting or analysing large amounts of data. Whether these data comprise questionnaire responses, radio telescope emissions, or genomic sequencing, there is a growing need for researchers to understand how to collect, store, archive and share their research data. These processes, collected under the Research Data Management (RDM) umbrella, are viewed by proponents of open data as a benefit for researchers, allowing them to build on previous research, collaborate with others, and further publicise their research (Doucette \& Fyfe, 2013; McKiernan et al., 2016).

At the university level, many research organisations are also realising the importance of RDM in ensuring that their intellectual property is kept safe, that research funding is providing value for money, and that research is transparent. Transparency in research is a growing concern ensuring that institutions reduce the chance of involvement in ethics violation scandals and countering the 'reproducibility crisis (Baker \& Penny, 2016). A further driver for 
research organisations' interest in RDM is the requirement of many major research funders that the management of research data is addressed as part of grant funding applications in a Data Management Plan (Pinfield, Cox, \& Smith, 2014). Some journals are also beginning to request that authors submit and consider sharing their data as part of the publication process (Vasilevsky, Minnier, Haendel, \& Champieux, 2017). As a consequence of these concerns, many universities have developed data policies over the last decade, although their existence is often not well advertised (Briney, Goben, \& Zilinski, 2015).

Pressure on researchers to meet RDM standards is increasing, however, it is only in the last ten years that RDM concepts have started to be taught to research students. These courses are often taught as an optional course as part of a continued professional development (CPD) programme (Parsons, 2013; Rice, 2014). As awareness around the importance of RDM has grown, the teaching of these concepts has become a much more important part of many training programs for postgraduate research students (PGRs), although much more needs to be done to embed data management training into all postgraduate programmes (Molloy \& Snow, 2012, p. 102). If current PGRs are the researchers of the future, then it is important to train them well in concepts such as RDM, in anticipation of an increasingly open research environment. In the UK, it is predominantly the libraries of research organisations that are involved in developing new institutional research data management advisory and training services (Cox \& Pinfield, 2014).

In 2012 the University of Nottingham (UoN) started delivering a comprehensive online training course to cover research data management topics for postgraduate research students (Parsons, 2013). The course, like those delivered by many other universities, was strongly based on the eight-unit MANTRA Research Data Management Training materials 
developed at the University of Edinburgh (Rice, 2014). Since late 2017, UoN has been in the process of updating and promoting its Digital Research and RDM services. As part of this project, Librarians in the UoN Libraries' Research Support Team were tasked with providing online RDM training for the Graduate School, and more importantly, reviewing this training to ensure that the training was 'fit for purpose', particularly in the wake of the new University RDM policy, the changing demands of research funders, and the implementation of the General Data Protection Regulation (GDPR) in late May 2018.

Both the technological resources and the theoretical pedagogy for online training has advanced greatly in the six years since the UoN RDM course was first launched. Furthermore, most PGR students have never known a world without internet-enabled technology. Online learning, which in its infancy was deemed to be engaging simply through novelty, must keep up with the expectations of students if it hopes to hold their interest on the subject matter. It was, therefore, important to assess existing university training in RDM, identify both its strengths and weaknesses, and update it accordingly, with reference to modern pedagogies, and to utilise new technologies. We hope that through this article our journey to develop a new exciting PGR focused online RDM course can make similar journeys, that other librarians are undertaking, simpler. The materials and programme we have created are included to provide educational tools for libraries which do not have the resources to undertake a similar re-design of their own courses. 


\section{LITERATURE REVIEW}

\section{RDM teaching}

RDM courses cover a range of topics: definitions of data and RDM; funding agency requirements and mandates; sharing and archiving data; copyright and ownership; metadata; and the reuse of shared data (Clement, Blau, Abbaspour, \& Gandour-Rood, 2017; Furukawa, Ojiro, \& Yamaji, 2018; Rice, 2014; Southall \& Scutt, 2017). Individual courses often only cover a subset of these broad categories. Training in creating a data management plan (DMP) is less often found in traditional PGR training, although is starting to be taken up by RDM programmes (Holles \& Schmidt, 2018). Training and advice on data management planning is instead frequently reserved for those who are currently writing a grant application that requires it (Johnston, Lafferty, \& Petsan, 2012).

Much of the RDM training described in the literature is of the 'train the trainer' variety (Schneider, 2017), it aims to upskill librarians or other research support staff to enable them to support researchers (Furukawa et al., 2018). Library staff do consistently record the need for upskilling in this area when asked about their careers (Goben \& Nelson, 2018; Nitecki \& Davis, 2017; Peters, 2017). PGR students form another significant cohort. A programme training teams of support staff, students and researchers found that teaching RDM to these groups together was particularly successful (Clement et al., 2017), as was the imbedding of librarians into research groups to identify specific needs and provide training in-situ (Lyon, 2016).

RDM courses primarily fall into two types of instruction format: workshops, either as a standalone course or as a series of sessions (Clement et al., 2017; Goben \& Nelson, 2018; Helbig, 2016; Peters, 2017; Southall \& Scutt, 2017); or online courses, allowing for learning to 
take place as it is convenient (Furukawa et al., 2018; Rice, 2014; Si, Xing, Zhuang, Hua \& Zhou, 2015) and whenever it becomes directly relevant to research practice (Ward \& Freiman, 2011, p. 269). Graduate RDM courses delivered as lecture series by librarians are rarer (Corrall, 2012; Whitmire, 2015), and this format is too resource-intensive for implementation in our institutional context.

RDM online courses seem to be of great interest, with greater numbers applying than would be expected (Furukawa et al., 2018). A fairly high number of these students take the courses through to completion (Furukawa et al., 2018) although the courses still suffer somewhat from the high dropout rates observed generally in online courses (Kennedy, 2014). However, a high rate of non-attendance of pre-booked courses is also seen in workshop format RDM courses; it has been suggested that this may be due to attendees being interested in the idea of the content, but not seeing the importance of the course and so not prioritising attendance over other commitments (Southall \& Scutt, 2017).

\section{Online Pedagogy}

Enrolment figures in the USA for online courses have risen for the last 14 years (Seaman, Allen, \& Seaman, 2018). Although MOOCs, Massively Open Online Courses, are the most widely discussed in the literature (De Freitas, Morgan, \& Gibson, 2015; Kennedy, 2014; Kizilcec, Saltarelli, Reich, \& Cohen, 2017; Littlejohn, Hood, Milligan, \& Mustain, 2016; Mahmod, Ali, \& Shah, 2018; Rodriguez, 2012), about $50 \%$ of learners who take online distance courses, also take non-distance courses from the same research organisation (Seaman et al., 2018). Universities have taken to online courses partly due to funding restrictions, but also due to student demand for convenience (Johnson, Mejia, \& Cook, 2015; McGee, Windes, \& Torres, 2017), although there is a wide disparity in institutional infrastructure and support around 
the teaching of these courses (Elliott, Rhoades, Jackson, \& Mandernach, 2015; Porter, Graham, Bodily, \& Sandberg, 2016). Faculty and instructors also vary in their support for and interest in teaching online (McGee et al., 2017), citing as barriers a lack of support (Keengwe, Kidd, \& Kyei-Blankson, 2009), job security (Birch \& Burnett, 2009), and technological demands (Birch \& Burnett, 2009), or falling into 'the trough of disillusionment' regarding e-learning (Friedland, Hürst, Knipping \& Muhlhäuser, 2009).

Online courses fall into two main types, they either follow a connectivist approach which incorporates social aspects to the course and provides a more distributed approach (Kennedy, 2014; Mahmod et al., 2018; Siemens, 2005), or a cognitive-behaviourist approach, which maps more closely to traditional higher education pedagogy, often described as 'content based' or 'instructor centric' (Kennedy, 2014; Mahmod et al., 2018; Rodriguez, 2012).

Online courses, particularly those which take a cognitive-behaviourist approach, often rely heavily on text and video resources to deliver content. Structured by the principle that 'knowledge' is external to the learner and that the process of learning is the act of internalising knowledge (Siemens, 2005), many of these courses simply 'webify' text books (Friedland, Hürst, Knipping \& Muhlhäuser, 2009). Yet technology used only to substitute or augment traditional pedagogy, without functional change or improvement, stalls learning completely (Puentedura, 2014).

Many online courses include tests to ensure that users have learnt the material (Furukawa et al., 2018). An advantage of the online format is that these tests can usually be automatically marked, saving instructor labour and time, which instructors value and perceive as a distinct advantage of virtual learning environments (Lonn \& Teasley, 2009). Where courses go even further than this and use practical activities, students are shown to have better learning 
outcomes (Freeman et al., 2014; Salmon, 2002; Wieman, 2014). Active learning behaviours have been shown to increase engagement with the course and the material (Dixson, 2015; Salmon, 2002) combating the high dropout rates that are seen in online courses (Kennedy, 2014).

\section{DESCRIPTION OF PROGRAM}

\section{Analysis of Existing Course}

\section{Content and Design}

The online RDM course available to University of Nottingham staff and students from 2012 to 2018 (Parsons, 2013) used the MANTRA Research Data Management Training (Rice, 2014) materials developed at the University of Edinburgh in 2011 and made available through a CCBY license. The content is detailed and accurate, created by experts, and comprehensively covers all topics which might be required (https://mantra.edina.ac.uk/).. This 2012 UoN Moodle course combined all eight MANTRA modules into a single course, includes text, video and interactive elements and each module is designed to take approximately one hour to complete.

The course provided texts to read, videos to watch, and fill-in-the-blanks quiz activities at the end of each unit to test whether students could recall the content and, to a lesser extent, that they understood the material. Modern pedagogical frameworks place these interactions at the lowest levels of the framework; Bloom's Revised Taxonomy (Krathwohl, 2002), for example, describes these as Lower Order Thinking Skills (LOTS).

Although innovative when originally developed, by 2018 the course materials appeared outdated in comparison to the newer online courses, delivered through Moodle, which the 
students are familiar with. We also felt that 8 hours was a long time for a PGR student to devote to RDM and that students were likely to become disengaged and fail to complete the course. While an appropriate time for a comprehensive course, it was decided that a shorter course would encourage more students to complete the course, increasing the student's overall knowledge, if not creating experts of them.

\section{User engagement}

As part of our analysis of the existing course, we acquired data on the number of students who had taken part in the course during the five academic years between 2013/2014 and 2017/2018. We also obtained detailed data on the enrolments which occurred between May 2018 and November 2018.. The number of enrolments and completions have increased over the last few years, likely due to students, and supervisors, recognising the importance of RDM.

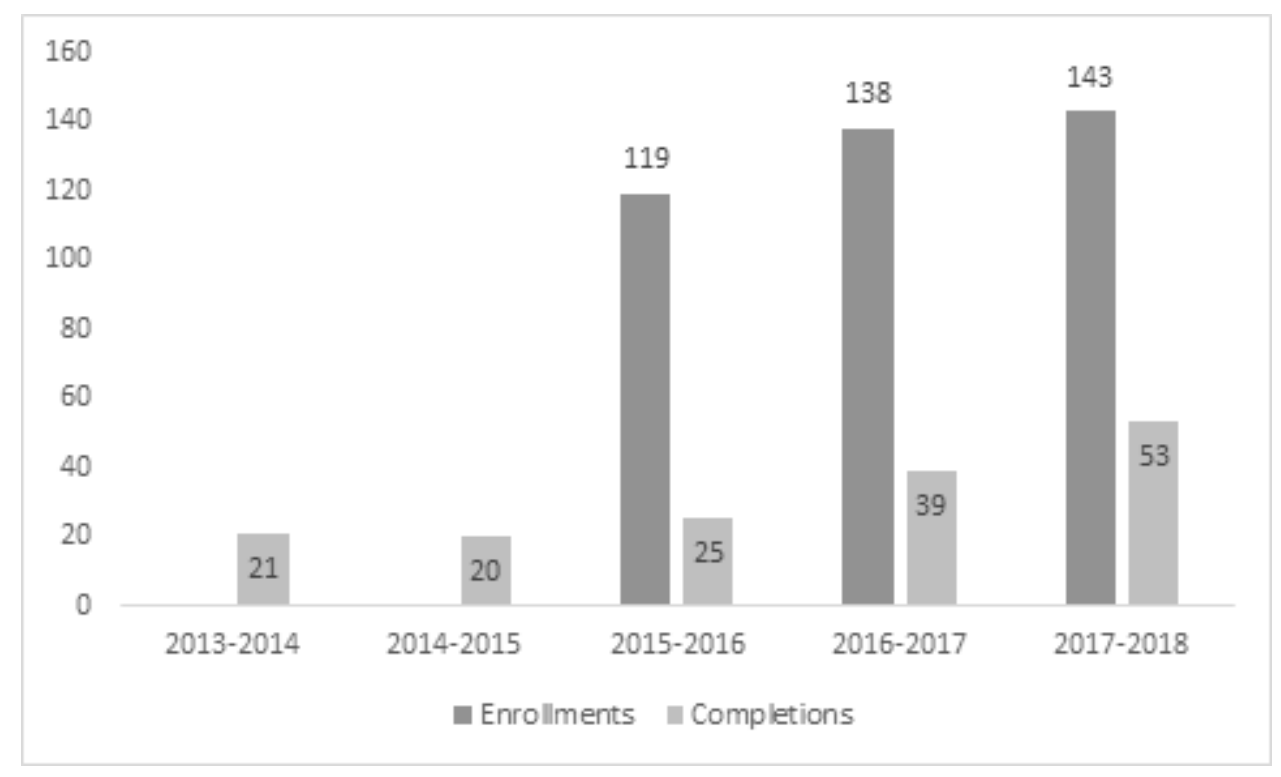

Figure 1. Barchart showing the number of enrolments and completions on the RDM online course. For the $2013 / 2014$ and $2014 / 2015$ academic year only the completion data is available. 
For the academic year $2017 / 2018$, the University of Nottingham had 1,001 first year PGR students registered and a total of 3,031 PGR students. Just under $5 \%$ of these students registered for the course during the year and under $2 \%$ completed the course (Figure 1). . Although there are also a small number of face-to-face training sessions available, we cannot help but draw the conclusion that the vast majority of PGR students at the University of Nottingham have been completing their studies and moving onto new roles, often within research, without ever having undertaken any formal RDM training.

During May 2018 to November 2018, 30 students completed the RDM course. An analysis of the time taken by these 30 students who had taken part in the RDM training shows that even out of the students who completed the course, many cannot have properly engaged with the material. Seventy percent of students completed the course in under an hour and for a quarter of the students this was under 10 minutes (Figure 2). Given that the course was expected to take 8 hours, it seems unlike that these students can have engaged with the material in any meaningful way.

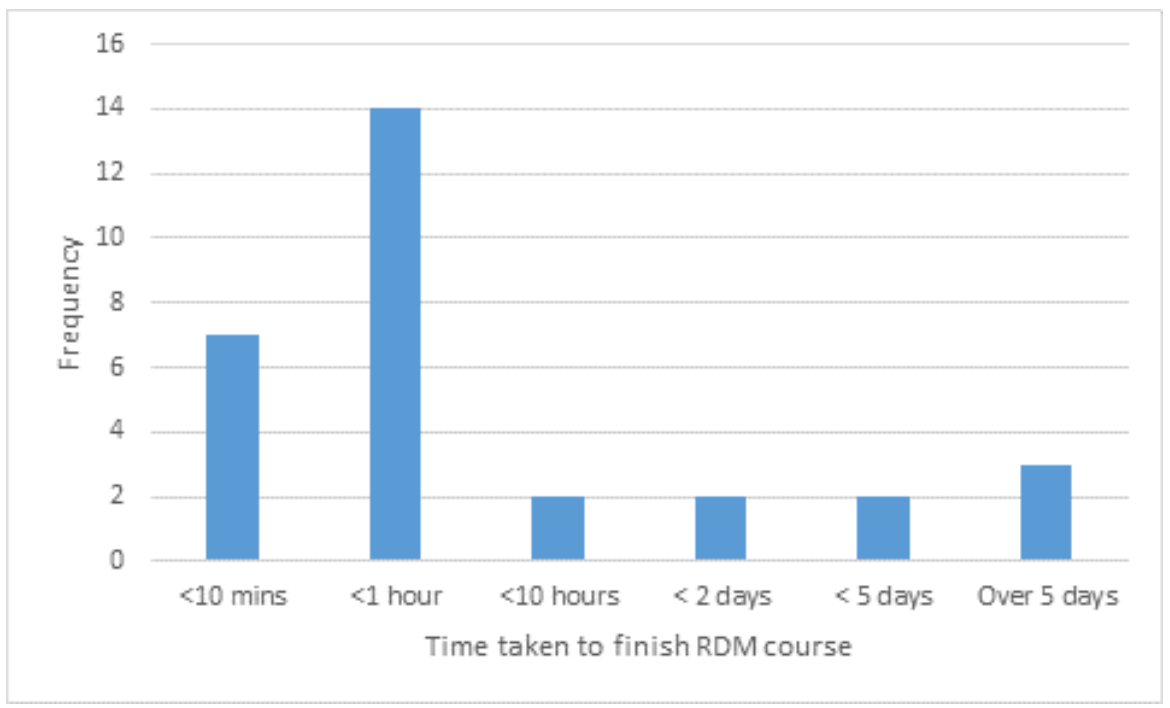

Figure 2. Time taken for students within the May - November 2017/2018 cohort to complete the online RDM course. 


\section{Design and Creation of New Course}

\section{Goals and Frameworks}

Due to the constantly-evolving nature of the higher education open research environment, we identified the need to use a connectivist model of learning, which enables learners to recognise when new information alters the landscape and adapt their knowledge to remain current in their field (Siemens, 2005). The course was designed using a backwards design framework (Langub \& Lokey-Vega, 2017; Wiggins, Wiggins, \& McTighe, 2005). The three points of consideration in the backwards design framework are (Wiggins et al., 2005):

1. The intended results of the instruction

2. The acceptable evidence that the student has achieved this result

3. The planning of learning experiences and instruction

Backwards Design: Stage 1 - Intended results

In the case of this course, we wanted the participants to be able to write a basic DMP for a current project, and to be able to be able to start future projects by writing a DMP, either with or without the aid of the course. Writing a DMP is an activity which all researchers at the University of Nottingham are required to engage in; it is often mandated by grant funding bodies and, more importantly, it ensures that other areas of research data management are addressed. In ensuring that a student is able to complete a DMP, the majority of other areas such as data collection, data storage, data archiving, copyright and licensing, and metadata, will also be covered. The ways in which these areas fit into the data management plan, and the course, can be seen in the course outline and sample DMP in the supplementary material. 
Backwards Design: Stage 2 - Acceptable Evidence

Two types of evidence were incorporated as part of each unit in the module: first, a short one or two question test (see supplementary materials), or, formative assessment, to ensure that the main points in each unit had been understood; and second, a task directy related to the intended result, in which the students were asked to write part of a DMP based on the topic addressed in that unit of the module. The DMP was self-marked against an 'answer' that became available once the student had checked the box to confirm they had completed the writing task (see supplementary materials). The 'answer' consists of prompt questions and information points that should be included in the DMP, for example, 'What file types will you be using?' and 'Do you have any data that needs to be anonymised?'.

Backwards design: Stage 3 - Learning experiences and instruction

The information in the course was delivered to participants in a variety of ways, including material and diagrams to read, videos, interactive reading lists linked to the library catalogue, and hyperlinks out to further resources. A glossary of terms was built which automatically linked to occurrences of particular terms throughout the module (e.g. 'licence', 'repository') to allow for a seamless introduction of new vocabulary.

The backwards design framework dovetails neatly with Bloom's revised Taxonomy (Anderson, Krathwohl, Airasian, Cruikshank, Mayer, et al., 2001). As a means of engaging students further with the RDM content, the new course was designed to employ the skills found higher on Bloom's revised Taxonomy: Applying, Analysing, Evaluating and Creating (Krathwohl, 2002). The previous course had ensured that students Remembered and Understood materials, but did not encourage these higher skills. The writing of a DMP as an integral part of the course utilises all of these skills (Table 1 ) via experiential learning. That is, our new design 
transformed the inert knowledge of the original course into working knowledge by orienting learning around tasks. The writing of the plan as the related activity ensures that research data management topics are not simply remembered, but 'applied', 'analysed' and 'evaluated' to ensure that that DMP fits their specific project. By writing sections of the DMP across the end of unit tasks of the course, the learner gradually 'creates' a coherent DMP of their own by combining the sections together. 


\begin{tabular}{|c|c|}
\hline $\begin{array}{l}\text { Revised Bloom's } \\
\text { Taxonomy }\end{array}$ & Activities within the RDM course \\
\hline Remember & $\begin{array}{l}\text { - Remember where to find advice on RDM } \\
\text { - Remember that data should be kept safe and secure } \\
\text { - Remember that data should be shared where possible }\end{array}$ \\
\hline Understand & $\begin{array}{l}\text { - Understand rights and responsibilities around sharing } \\
\text { and licenses } \\
\text { - Understand why you should write a DMP } \\
\text { - Understand how to keep your data safe and secure }\end{array}$ \\
\hline Apply & $\begin{array}{l}\text { - Apply knowledge to situational questions in quizzes } \\
\text { - Apply knowledge of University policies to write the } \\
\text { DMP sections }\end{array}$ \\
\hline Analyse & $\begin{array}{l}\text { - Analyse which license would be appropriate for your } \\
\text { data (as part of writing a DMP) } \\
\text { - Analyse data management procedures to see where } \\
\text { future problems lie (as part of writing a DMP) }\end{array}$ \\
\hline Evaluate & - Evaluate DMP answers against a 'gold standard' \\
\hline Create & $\begin{array}{l}\text { - Create entire DMP based on own research project } \\
\text { - Be able to create DMPs for future research projects, } \\
\text { with or without relying on extra resources }\end{array}$ \\
\hline
\end{tabular}

Table 1. A mapping of activities occurring during the course and how these map to the Revised Bloom's Taxonomy. 


\section{Implementation}

It was decided that the learning platform Moodle was the most appropriate vehicle to deliver the new RDM course for two reasons; the University of Nottingham already uses Moodle across all Schools and Faculties as its virtual learning environment; and University of Nottingham students are familiar with the format of Moodle from previous courses they have taken. Following Krug's primary web usability guideline of "Don't Make Me Think" (Krug, 2006, p11), this familiar format would allow students to save their learning energy for the RDM content rather than spending it familiarising themselves with the vehicle. Although the previous course had also been delivered by the Graduate School via Moodle, the course design did not take advantage of the features provided by the platform. In order to ensure that the RDM course was open and available to all, all text and material created for or included in the course was checked for accessibility using the accessibility-checker feature provided by Moodle. This ensured that pages were read in the correct order by screen reading software and that all pictures and videos included captions. We also consulted the Accessibility Support Librarian for additional guidance.

Initial preparation for the course involved engaging with, and learning best practice associated with, the technology available for online learning at the University of Nottingham. The Research Librarian attended a half-day hands-on 'Key Moodle Basics' training course and completed a 5-week standalone online course on 'Designing for Engagement' delivered wholly via Moodle by the Learning Technologies team, to learn more about Moodle design and the student experience. To learn more about creating a standalone online course, we also met with staff from Learning Technologies to gain an insight into which of the many types of features and activities available through the Moodle platform students engaged with well. 
After an assessment of the features and activities used in similar online postgraduate courses we settled on the use of mini quizzes, a final module assessment quiz, videos, and pictures. The primary end of unit 'task' activity we decided to design ourselves, creating sub-pages which asked students to write sections of the Data Management Plan as they worked through the course. We needed to design a self-sustaining (i.e., no facilitation by staff required) and asynchronous course, on which students could enrol at any time, and take as long as they needed to complete. We, therefore, used quizzes which automatically graded students, and for each of the end of unit 'tasks' we created 'answer' sections which would appear once the student had confirmed that they had completed the activities, allowing the students to selfmark. To gain credit for the course (an optional feature for postgraduates), students also needed to complete a summative assessment at the end of the course. This consisted of ten multiple-choice questions which were automatically graded. The end of unit formative assessments and the end of module summative assessments were designed to be complementary, following principles of 'Constructive Alignment' (Biggs, 1996; Biggs and Tang, 2011). That is, each of the low-stakes formative assessments prepared students for the final assessment and enabled them to meet the learning outcomes.

A decision was made to reduce the length of the course. The analysis of completion rates showed that many students were not finishing the current course and were likely missing the topics and concepts covered at the end. The new course was to take approximately 3 hours, a much more realistic timeframe to expect PGR students to devote to RDM. The reduction of content in turn meant that a further decision needed to be made regarding the selection of material: what was the most important and relevant material for learners? This decision was made with reference to the first stage of the backwards design framework: what was needed to ensure that students were able to write a DMP? Much of the information about policies, 
qualitative and quantitative research methods, and the broader context of the open research landscape was removed in favour of practical information that would have direct relevance to the research postgraduates were undertaking. Links to further information and an annotated reading list were included for the interested student, but it was not made compulsory to engage with this material for the student to complete the course.The new course consisted of seven modules: Introduction to Research Data Management; Introduction to Data Management Plans; Data collection and description, including sensitive or personal data; Storage and security; Organising your data and creating metadata; Data preservation and archiving; and Publication and sharing (See supplementary materials course outline for further details). These topics were chosen both through an analysis of the researcher obligations embedded within the University of Nottingham's Research Data Management Policy (and so ensuring that the students understood the most important information in the policy without having to read it), and by dividing the University of Nottingham's institutional DMP template into manageable sections. Ensuring that all the material in the course was directly relevant to understanding the practicalities of RDM and understanding how to write a DMP in turn increases the likelihood of students staying engaged with the material.

\section{Obtaining Feedback and evaluating the course}

Once the first draft of the course had been created, a library colleague was invited to enroll on the course for usability testing and to provide feedback. A 'Think-Aloud protocol' was used to elicit feedback on the usability, design and content of the course. That is, using the thinkaloud protocol, we asked the usability tester to make their way through the course as if they were a student, and say whatever came into their mind as they read the material, completed the quizzes, and moved from unit to unit. The Research Librarian made notes to capture the 
comments and used these as a basis to form a list of necessary edits, changes, and suggested improvements for design, content, and navigability. The tester navigated the course differently than we had assumed students would when we created it, and because of this identified a number of areas where instructions were not clear, or where the content of the course did not run smoothly from one page to the next. This usability testing was essential in ensuring that the students did not come across any technical difficulties while attempting to complete the course. These difficulties can de-rail a student's concentration and may even cause the student to give up on the course all together; using online learning tools badly or for novelty value has been shown to reduce impactful learning significantly or produce no learning effect at all (Fies \& Marshall, 2006; Crouch \& Mazur, 2001).

The final version of the course also contains a feedback form. The majority of the questions are those found on the National Student Survey (NSS). The feedback form also employs a Likert-scale to measure learner attitudes, and the same options as those found on the NSS are provided as responses (https://www.thestudentsurvey.com/content/NSS2017 Core Questionnaire.pdf). Again, this ensures that students are familiar with the format of the questions, and it will enable the course to be compared to other teaching at the University, although the cohort for this course will not be final year undergraduates as it would be for the NSS.

We have also included some questions to attempt to determine whether the course has completed its goal of teaching participants about RDM, and in particular, whether the course has provided them with the skills to enable them to write DMPs for future research projects.

Question 10: On a scale of 0 (low) to 10 (high) how would you rate your knowledge of RDM prior to taking the course? 
Question 11: On a scale of 0 (low) to 10 (high) how would you rate your knowledge of RDM now you have completed the course?

Question 12: Would you now feel confident to complete a DMP for a research project?

- Yes, very confident

- Yes, with the help of resources

- Not confident, but l'll give it a go

- Not at all confident

At the time of writing, 9 feedback questionnaires had been completed, these showed a reported increase from an average RDM knowledge rating of 5.33 before the course to a rating of 8.25 after completing the course. Of the 9 completed students, 7 stated that "The module provided me with opportunities to apply what I have learned" and all stated that they would be confident to complete a DMP with the help of resources.

Initial 3 month assessment of the Course

151 students and staff enrolled on the new RDM course from its launch at the last week of January 2019 to the last week of May 2019. Of these (70) have engaged with at least one section of the course, although in some cases this is the pre-course information such as learning objectives, (27) have completed the final assessment. When compared to the 2017/2018 year figures, our course has both a higher enrollment (expected number is 48 in 4 months), and completion (expected 18 in 4 months) rate than the previous course. However, it is important to assume that a new, well publicised course will garner more attention than a course which has existed for several year. Continued monitoring will tell whether this higher rate of interest is sustainable. 
The completion rate of the different pages and activities (Figure 3) show that while many participants have approached the course in a linear fashion, this was not always the case, for example '6.1 Archiving your data' and '7.1. Publishing your data' were completed by more participants than some of the pages from sections earlier in the course. As we continue with this course, and continue to monitor participation, these statistics will help to determine which are the topics, and activities, that the participants are most interested in.

One assumption that was made was that the students might skip straight to the quizzes, thus missing any further details provided by the course. However, the statistics from the first four months of the course show that the quiz activities in each section are those that the participants are least likely to complete. We believe this is associated with the low rate of final completion - many of our early participants have been university staff and researchers who are using the course to address holes in their knowledge, but not to gain training points and therefore do not feel the need to complete the quizzes. The DMP sections were viewed, and completed, much more often than the quiz sections supporting our decision to include practical assessments in the course. 


\section{Completion of Course Sections}

$\begin{array}{llllllllllll}0 & 5 & 10 & 15 & 20 & 25 & 30 & 35 & 40 & 45 & 50\end{array}$

Research Data Managem Outcomes Moodle Help for students Course resource list

1.1 Introduction to Research Data Management (RDM)

1.2 Video: Data Sharing and Management Snafu 1.3 Research data life-cycle 1.4 Video: UK Data Service: the research data life-cycle 1.5 Quiz: What is Data?

2.1 What is a Data Management Plan? 2.2 Quiz: When should I write my Data Management... Now let's start creating your Data Management Plan...

2.3 University of Nottingham Data Management Plan 3.1 Data Collection and Description 3.2 Using personal data in your research 3.3 Anonymising or Pseudonymising Data 3.4 Legal and Ethical Issues 3.5 Quiz: Data Collection 3.6 DMP Task: Data Collection 3.7 Review your answer 4.1 Storing your data safely and securely 4.2 Storing sensitive data 4.3 Data Storage Solutions 4.4 Quiz: Storage and Security 4.5 DMP Task: Storage and security 4.6 Review your answer 5.1 Organising your data 5.2 More thoughts on organising your data 5.3 Metadata

5.4 Data Documentation 5.5 Quiz: Organising your Data 5.6 DMP Task: Organising and Metadata 5.7 Review your answer 6.1 Archiving your data 6.2 Blog post: Is withholding your data bad science? 6.3 Selecting data to archive 6.4 Choosing where to archive your data 6.5 How to archive your data 6.6 Quiz: Archiving your data 6.7 DMP Task: Data preservation 6.8 Review your answer

7.1 Publishing your data

7.2 Data Access Statements

7.3 Restricting access to data

7.4 Quiz: Publication and sharing 7.5 DMP Task: Publication and sharing 7.6 Review your answer Congratulations! You have now written a Data Manag... Research Data Management Assessment Research Data Management UK: Module feedback

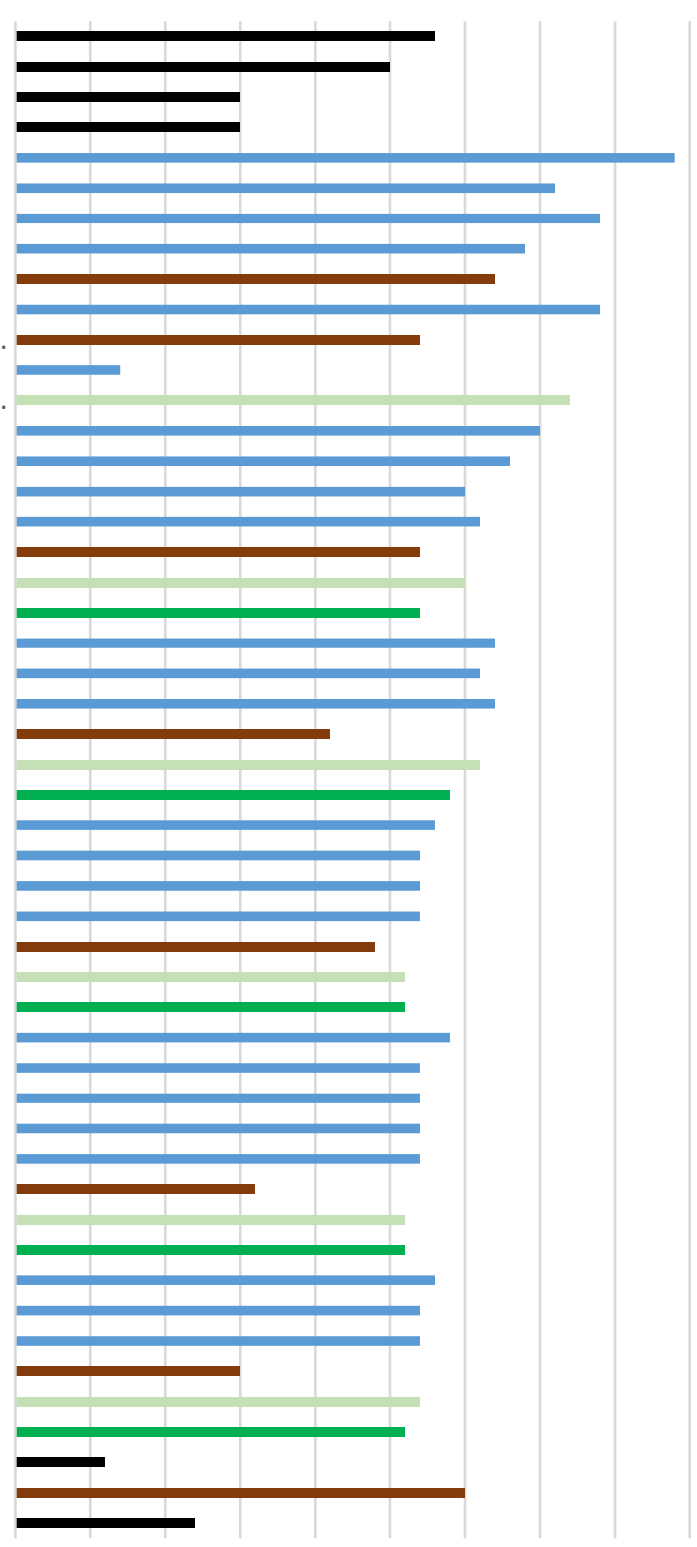

Figure 3. Frequency of section completion for the RDM course. Types of content are colour coded: Black - course information, Blue - content page, Brown - quiz assessment, Dark Green - DMP assessment, Light Green - DMP answers. 
12 course participants have completed the feedback form, this only gives us an indicative assessment of the course, but we will continue to assess the course as more feedback is received. All of these participants self-reported an increase in RDM knowledge, even those who had assessed their initial knowledge highly.

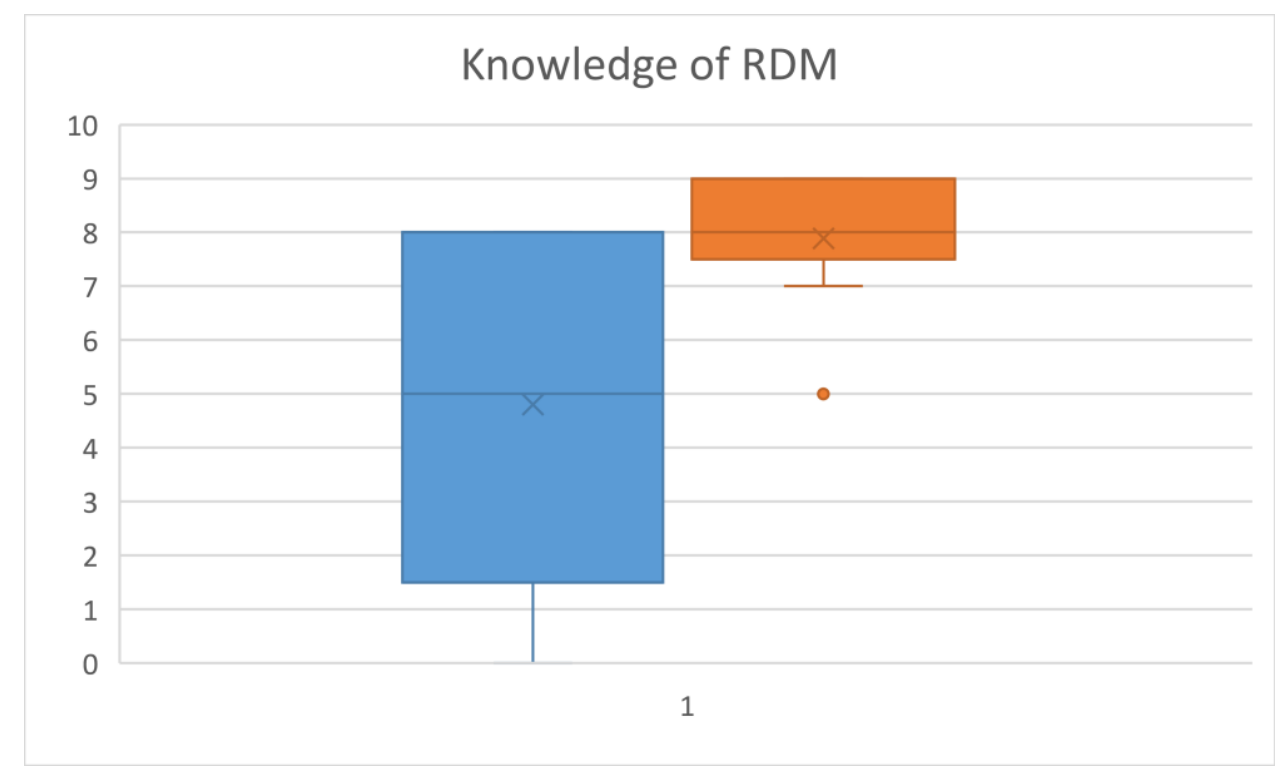

The level of RDM knowledge that students assessed themselves as having prior to taking the course was very disparate, with the highest at 8 and the lowest at 0 . After the course al participants rated themselves as having a greater knowledge of RDM, and 9 respondents stated that they would be comfortable writing a DMP in future with the aid of resources, 1 of the respondents stated that they weren't confident but that they would give it a go.

The NSS style evaluation of the course has shown some areas which need to be improved in future. Only $25 \%$ of those who completed the assessment felt that the material was intellectually stimulating and challenging. However, $75 \%$ of the respondents believed that the course was interesting and relevant however, so it may be that further formative assessments would improve this assessment. 


\section{NEXT STEPS}

\section{Advertising and engagement}

After creating the course and making it live on 1 February 2019, the next step is to ensure that the research community knows about this new resource. Ensuring that messages reach students and staff in Higher Education institutions can be difficult, and so we intend to use a multi-pronged attack. The course will be advertised on a number of University blogs and news outlets, it will be advertised through the Graduate School, and we will be utilising the working relationships that our Research Librarians have with Schools and Faculties across the University.

\section{Assessment of the Course and needs of the participants}

Obtaining detailed feedback from participants is often difficult. Currently our module feedback form is only available to those who have completed the final assessment, however this does not allow us to capture information from individuals who are only interested in using the course for a specific subset of the information. In the future this will be changed to allow feedback at any time with students being asked if they have completed the final assessment as a question in the feedback form.

Over the next year we intend to continue to monitor the enrolment and completion rates on the RDM course and compare them to those collected for the previous course.An analysis of the course will hopefully allow us to determine which areas of RDM are of particular concern for the research community at the University of Nottingham, and may lead to further comprehensive training around these issues. As part of this analysis we intend to conduct interviews with participants to allow us to further understand their motivations in engaging with the course. 


\section{CONCLUSIONS}

Engaging with both theory and practice around the development of a new moodle course has allowed us to create a course which is far superior to that which the University was previously providing, and as a result we hope that it will improve the levels of knowledge around RDM across the whole University. We were particularly surprised by the level of interest that this course has garnered from those outside of the intended audience. The course was intitially intended to be a replacement for the PGR teaching which had previously been run, however there has been significant interest from researchers and support staff who feel they do not have another avenue through which to learn about RDM.

In presenting this paper, we hope that we have provided a template on which other librarians would be able to model future courses. The course is built around strong theoretical foundations, but has also been assessed for practicality, it provides engaging and informative content to the participants in a practical way that many online course have not previously addressed. As such this course should provide high returns in student learning for a low level of staff resources needed. 


\section{References}

Anderson, L., Krathwohl, D., Airasian, P., Cruikshank, K., Mayer, R., Pintrich, P., Raths, J. \& Wittrock, M. (2001). A taxonomy for learning, teaching, and assessing: A revision of Bloom's taxonomy of educational objectives. New York: Longman. Retrieved from https://www.pearson.com/us/higher-education/program/Anderson-Taxonomy-forLearning-Teaching-and-Assessing-A-A-Revision-of-Bloom-s-Taxonomy-of-

\section{Educational-Objectives-Abridged-Edition/PGM200120.html.}

Baker, M., \& Penny, D. (2016). Is there a reproducibility crisis? Nature, 533(7604), 452-454. https://doi.org/10.1038/533452A

Biggs, J. (1996). Enhancing teaching through constructive alignment. Higher Education, 32, 347-364. Retrieved from https://www.jstor.org/stable/3448076

Biggs, J. \& Tang, C. (2011). Teaching for quality learning at university. $4^{\text {th }}$ ed. Maidenhead: Open University Press.

Birch, D., \& Burnett, B. (2009). Bringing academics on board: Encouraging institution-wide diffusion of e-learning environments. Australasian Journal of Educational Technology, 25(1), 117-134. Retrieved from http://citeseerx.ist.psu.edu/viewdoc/download?doi=10.1.1.363.6087\&rep=rep1\&typ $\underline{e=p d f}$.

Briney, K., Goben, A., \& Zilinski, L. (2015). Do You Have an Institutional Data Policy? A Review of the Current Landscape of Library Data Services and Institutional Data Policies. Journal of Librarianship and Scholarly Communication, 3(2), eP1232. http://doi.org/10.7710/2162-3309.1232 
Clement, R., Blau, A., Abbaspour, P., \& Gandour-Rood, E. (2017). Team-based data management instruction at small liberal arts colleges. IFLA Journal, 43(1), 105-118. https://doi.org/10.1177/0340035216678239

Corrall, S. (2012). Roles and responsibilities: libraries, librarians and data. In G. Pryor (Ed.), Managing Research Data (105-134). London: Facet.

\section{http://facetpublishing.co.uk/title.php?id=047562\#.XJlv-ij7TIV}

Cox, A., \& Pinfield, S. (2014). Research data management and libraries: Current activities and future priorities. Journal of Librarianship and Information Science, 46(4), 299-316.

\section{https://doi.org/10.1177/0961000613492542}

Crouch, C. \& Mazur, E. (2001). Peer Instruction: Ten years of experience and results. American Journal of Physics, 69(9), 970-977. https://doi.org/10.1119/1.1374249

De Freitas, S. I., Morgan, J., \& Gibson, D. (2015). Will MOOCs transform learning and teaching in higher education? Engagement and course retention in online learning provision. British Journal of Educational Technology, 46(3), 455-471.

\section{https://doi.org/10.1111/bjet.12268}

Dixson, M. D. (2015). Measuring Student Engagement in the Online Course: The Online Student Engagement Scale (OSE). Online Learning, 19(4), n4. Retrieved from

\section{https://eric.ed.gov/?id=EJ1079585}

Doucette, L., \& Fyfe, B. (2013). Drowning in research data: Addressing data management literacy of graduate students. Paper presented at the Imagine, Innovate, Inspire: The Proceedings of the ACRL 2013 Conference. Retrieved from http://www.ala.org/acrl/sites/ala.org.acrl/files/content/conferences/confsandpreco nfs/2013/papers/DoucetteFyfe Drowning.pdf 
Elliott, M., Rhoades, N., Jackson, C. M., \& Mandernach, B. J. (2015). Professional Development: Designing initiatives to meet the needs of online faculty. Journal of Educators Online, 12(1), n1. Retrieved from https://eric.ed.gov/?id=EJ1051031

Fies, C. \& Marshall, J. (2006). Classroom Response Systems: A Review of the Literature. Journal of Science Education and Technology, 15(1), 101-109.

\section{https://doi.org/10.1007/s10956-006-0360-1}

Freeman, S., Eddy, S. L., McDonough, M., Smith, M. K., Okoroafor, N., Jordt, H., \& Wenderoth, M. P. (2014). Active learning increases student performance in science, engineering, and mathematics. Proceedings of the National Academy of Sciences, 111(23), 8410. https://doi.org/10.1073/pnas.1319030111

Friedland, G., Hürst, W., Knipping, L. \& Muhlhäuser, M. (2009). Can We Escape the Trough of Disillusionment? eLearn Magazine. Retrieved from https://elearnmag.acm.org/featured.cfm?aid=1554532

Furukawa, M., Ojiro, K., \& Yamaji, K. (2018, 9-12 Oct. 2018). Development and Analysis of Online RDM Training Course. Paper presented at the 2018 IEEE 7th Global Conference on Consumer Electronics (GCCE). https://doi.org/10.1109/GCCE.2018.8574478

Goben, A., \& Nelson, M. S. (2018). Teaching Librarians About Data: The ACRL Research Data Management Roadshow. College \& Research Libraries News, 79(7), 354. Retrieved from https://crln.acrl.org/index.php/crlnews/article/view/17053/18805

Helbig, K. (2016). Research Data Management Training for Geographers: First Impressions. ISPRS International Journal of Geo-Information, 5(4), 40. https://doi.org/10.3390/ijgi5040040 
Holles, J. H., \& Schmidt, M. L. (2018). Graduate Research Data Management Course Content: Teaching the Data Management Plan (DMP). Paper presented at the 2018 ASEE Annual Conference \& Exposition. Retrieved from https://www.asee.org/public/conferences/106/papers/21191/view

Johnson, H. P., Mejia, M. C., \& Cook, K. (2015). Successful online courses in California's community colleges: Public Policy Institute. Retrieved from https://www.luminafoundation.org/files/resources/successful-online-courses-incali.pdf

Johnston, L., Lafferty, M., \& Petsan, B. (2012). Training researchers on data management: A scalable, cross-disciplinary approach. Journal of eScience Librarianship, 1(2), 2.

\section{https://doi.org/10.7191/jeslib.2012.1012}

Keengwe, J., Kidd, T., \& Kyei-Blankson, L. (2009). Faculty and technology: Implications for faculty training and technology leadership. Journal of Science Education and Technology, 18(1), 23-28. https://doi.org/10.1007/s10956-008-9126-2

Kennedy, J. (2014). Characteristics of massive open online courses (MOOCs): A research review, 2009-2012. Journal of Interactive Online Learning, 13(1). Retrieved from https://eric.ed.gov/?id=EJ1032981

Kizilcec, R. F., Saltarelli, A. J., Reich, J., \& Cohen, G. L. (2017). Closing global achievement gaps in MOOCs. Science, 355(6322), 251-252.

\section{https://doi.org/10.1126/science.aag2063}

Krathwohl, D. R. (2002). A revision of Bloom's taxonomy: An overview. Theory into practice, 41(4), 212-218. Retrieved from https://eric.ed.gov/?id=EJ667155

Krug, S. (2006). Don't make me think!: a common sense approach to Web usability (2 ${ }^{\text {nd }}$ ed.). Berkley, CA: New Riders. 
Langub, L. W., \& Lokey-Vega, A. (2017). Rethinking Instructional Technology to Improve Pedagogy for Digital Literacy: A Design Case in a Graduate Early Childhood Education Course. TechTrends, 61(4), 322-330. https://doi.org/10.1007/s11528-017-0185-1

Littlejohn, A., Hood, N., Milligan, C., \& Mustain, P. (2016). Learning in MOOCs: Motivations and self-regulated learning in MOOCs. The internet and Higher education, 29, 40-48. https://doi.org/10.1016/j.iheduc.2015.12.003

Lonn, S. \& Teasley, S. (2009). Saving Time or Innovating Practice: Investigating Perceptions and uses of Learning Management Systems. Computers \& Education, 53(3), 686-694. https://doi.org/10.1016/i.compedu.2009.04.008

Lyon, L. (2016). Librarians in the lab: Toward radically re-engineering data curation services at the research coalface. New Review of Academic Librarianship, 22(4), 391-409. https://doi.org/10.1080/13614533.2016.1159969

Mahmod, M. A., Ali, A. M., \& Shah, A. (2018). Massive Open Online Courses as an Augmentation of E-Learning: A Review. International Journal on Perceptive and Cognitive Computing, 4(2), 1-4. Retrieved from

\section{http://journals.iium.edu.my/kict/index.php/IJPCC/article/download/69/51}

McGee, P., Windes, D., \& Torres, M. (2017). Experienced online instructors: beliefs and preferred supports regarding online teaching. Journal of Computing in Higher Education, 29(2), 331-352. https://doi.org/10.1007/s12528-017-9140-6

McKiernan, E. C., Bourne, P. E., Brown, C. T., Buck, S., Kenall, A., Lin, J., . . Soderberg, C. K. (2016). Point of view: How open science helps researchers succeed. Elife, 5, e16800. http://doi.org/10.7554/eLife.16800.001 
Molloy, L. \& Snow, K. (2012). The Data Management Skills Support Initiative: Synthesising Postgraduate Training in Research Data Management. International Journal of Digital Curation, 7(2), 101-109. https://doi.org/10.2218/ijdc.v7i2.233

Nitecki, D. A., \& Davis, M. E. K. (2017). Changing Landscapes: New Roles for Academic Librarians. Retrieved from http://library.ifla.org/id/eprint/1833

Parsons, T. (2013). Creating a Research Data Management Service. IJDC, 8(2), 146-156.

\section{https://doi.org/10.2218/ijdc.v8i2.279}

Peters, C. (2017). Upskilling Academic Librarians for Data Management Services. Paper presented at: IFLA WLIC 2017 - Wrocław, Poland - Libraries. Solidarity. Society.

\section{http://library.ifla.org/id/eprint/1724}

Pinfield, S., Cox, A. M., \& Smith, J. (2014). Research Data Management and Libraries:

Relationships, Activities, Drivers and Influences. PLOS ONE, 9(12), e114734.

https://doi.org/10.1371/journal.pone.0114734

Porter, W. W., Graham, C. R., Bodily, R. G., \& Sandberg, D. S. (2016). A qualitative analysis of institutional drivers and barriers to blended learning adoption in higher education. The internet and Higher education, 28, 17-27.

https://doi.org/10.1016/j.iheduc.2015.08.003

Puentedura, R. (2014). Learning, technology, and the SAMR model: Goals, processes, and practice. Retrieved from http://hippasus.com/resources/tte/

Rice, R. (2014). Research data MANTRA: A labour of love. Journal of eScience Librarianship, 3(1), 4. http://doi.org/10.7191/jeslib.2014.1056

Rodriguez, C. O. (2012). MOOCs and the Al-Stanford Like Courses: Two Successful and Distinct Course Formats for Massive Open Online Courses. European Journal of Open, Distance and E-Learning. Retrieved from https://eric.ed.gov/?id=EJ982976 
Salmon, G. (2002) E-tivities: the key to active online learning. London: Routledge, Falmer. Schneider, R. (2017). Training Trainers for Research Data Literacy: A Content-and MethodOriented Approach. . In: Kurbanoğlu S., Boustany J., Špiranec S., Grassian E., Mizrachi D., Roy L. (eds) Information Literacy in the Workplace. ECIL 2017. Communications in Computer and Information Science, 810. Springer, Cham.

\section{https://doi.org/10.1007/978-3-319-74334-9 15}

Seaman, J. E., Allen, I. E., \& Seaman, J. (2018). Grade Increase: Tracking Distance Education in the United States. Babson Survey Research Group. Retrieved from https://onlinelearningsurvey.com/reports/gradeincrease.pdf

Si, L., Xing, W., Zhuang, X., Hua, X., \& Zhou, L. (2015). Investigation and analysis of research data services in university libraries. The Electronic Library, 33(3), 417-449.

\section{https://doi.org/10.1108/EL-07-2013-0130}

Siemens, G. (2005). Connectivism: A Learning Theory for the Digital age. International Journal of Instructional Technology and Distance Learning, 2(1), 3-10. Retrieved from http://www.itdl.org/journal/jan_05/article01.htm

Southall, J., \& Scutt, C. (2017). Training for Research Data Management at the Bodleian Libraries: National Contexts and Local Implementation for Researchers and Librarians. New Review of Academic Librarianship, 23(2-3), 303-322.

\section{https://doi.org/10.1080/13614533.2017.1318766}

Vasilevsky, N. A., Minnier, J., Haendel, M. A., \& Champieux, R. E. (2017). Reproducible and reusable research: are journal data sharing policies meeting the mark? PeerJ, 5, e3208. https://doi.org/10.7717/peerj.3208 
Ward, C. \& Freiman, L. (2011). Making Sense: Talking Data Management with Researchers. The International Journal of Digital Curation, 2(6), 265-273. Retrieved from http://www.ijdc.net/article/view/197/262

Whitmire, L. (2015). Implementing a Graduate-Level Research Data Management Course: Approach, Outcomes, and Lessons Learned. Journal of Librarianship and Scholarly Communication, 3(2), eP1246. http://doi.org/10.7710/2162-3309.1246

Wieman, C. E. (2014). Large-scale comparison of science teaching methods sends clear message. Proceedings of the National Academy of Sciences, 111(23), 8319. https://doi.org/10.1073/pnas.1407304111

Wiggins, G., Wiggins, G. P., \& McTighe, J. (2005). Understanding by design. Alexandria, VA: Ascd. 